\title{
International Factor Mobility and Dynamic Paths
}

\author{
Hiroshi Goto, Yuji Matsuoka \\ Graduate School of Economics, Kobe University, Kobe, Japan \\ Email: 081e108e@stu.kobe-u.ac.jp
}

Received October 25, 2013; revised November 25, 2013; accepted December 2, 2013

Copyright (c) 2013 Hiroshi Goto, Yuji Matsuoka. This is an open access article distributed under the Creative Commons Attribution License, which permits unrestricted use, distribution, and reproduction in any medium, provided the original work is properly cited. In accordance of the Creative Commons Attribution License all Copyrights (C) 2013 are reserved for SCIRP and the owner of the intellectual property Hiroshi Goto, Yuji Matsuoka. All Copyright (C) 2013 are guarded by law and by SCIRP as a guardian.

\begin{abstract}
The aim of this paper is to consider the adjustment process of the spatial structure in a two-country economy where both labor and capital are mobile. For this purpose, we combine the model of New Economic Geography with the phase diagram technique. We show that the agglomeration processes are not always monotonic since the mobile factors interact with each other. More specifically, even when both factors are eventually agglomerated to one country, it is possible that labor and capital move in opposite directions in the adjustment process. Differences in factor endowment ratio and market size play significant roles in this transition path.
\end{abstract}

Keywords: Labor Mobility; Capital Mobility; Spatial Equilibrium; Adjustment Process; Phase Diagram

\section{Introduction}

This paper examines dynamic paths of agglomeration. We construct a two-country, two-good, and two-factor model, and let both factors move between countries gradually. Because the adjustment processes of the two factors interact with each other, we expect that dynamic paths of agglomeration would become complex.

Related to our concerns, the New Economic Geography (NEG) literature has provided rich theoretical insights on the factor mobility and distribution of economic activity across the geographical space. However, while it has mainly focused on spatial equilibrium, it seldom presents explicit details on dynamic paths of agglomeration. This paper aims at filling the gap ${ }^{1}$.

Our results show that agglomeration processes are not always monotonic. When the difference in the factor endowment ratio between countries is large, the factors are adjusted toward the symmetric equilibrium, reducing the factor endowment differentials. Once the difference becomes sufficiently small, both factors are fully agglomerated to one country because of the scale merit. As a result, dynamic paths of agglomeration acquire a distorted shape.

The remainder of this paper is organized as follows. Section 2 presents the model. In Section 3, we describe

${ }^{1}$ We can refer to Baldwin and Venables [1] as a related paper. To consider the international factor mobility, they have shed light on roles of distortion and expectation, while the key factors in our model are factor endowment ratio and market size. See their paper for more details. the transition of the spatial structure. Section 4 concludes.

\section{The Model}

Our model is based on the footloose capital model, which is established by Martin and Rogers [2]. We consider an economy with two countries (Home and Foreign), which are denoted by $H$ and $F$, respectively. In this economy, there are two sectors: one is the homogeneous agricultural goods sector and the other is the differentiated manufactured goods sector.

We assume that there are $L$ individuals. Each individual owns one unit of labor and one unit of capital and decides where to live and invest. The preference of an individual is represented by the following Cobb-Douglas utility function:

$$
U=\frac{1}{\mu^{\mu}(1-\mu)^{1-\mu}} M^{\mu} A^{1-\mu}
$$

where $\mu$ is the share of expenditure on manufactured goods, $A$ is the consumption of agricultural goods, and $M$ is the quantity index of manufactured goods. The quantity index of manufactured goods takes the following Dixit and Stiglitz [3] type CES function:

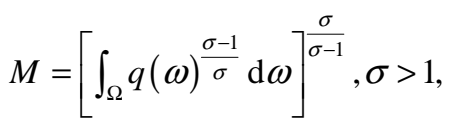


where $\Omega$ is the set of varieties in the manufacturing sector, $q(\omega)$ is the consumption of variety $\omega \in \Omega$, and $\sigma$ is the elasticity of substitution among varieties. Then, the well-known price index corresponding to $M$ is written as follows:

$$
P=\left[\int_{\Omega} p(\omega)^{1-\sigma} \mathrm{d} \omega\right]^{\frac{1}{1-\sigma}},
$$

where $p(\omega)$ is the price of variety $\omega$.

Next, we describe producers' behavior. In the agricultural sector, labor is the only input and technology provides constant returns to scale; hence, one unit of labor is required for one unit of output. We assume that this sector is perfectly competitive and that agricultural goods can be traded between countries at zero transportation cost. If we use this agricultural good as the numeraire, as long as it is produced in both countries, the wage rate in both countries can be fixed to unity.

Firms in the manufacturing sector use one unit of capital as the fixed input and $a$ units of labor as the marginal input. We further assume an iceberg-type transportation cost $(\tau>1)$ in the trade of differentiated manufactured goods between countries.

The profit function of each firm $\omega \in \Omega$ located in country $i(i=H, F)$ is

$$
\begin{aligned}
\pi_{i}(\omega) & =p_{i i}(\omega) q_{i i}(\omega)+p_{i j}(\omega) q_{i j}(\omega) \\
& -a\left[q_{i i}(\omega)+\tau q_{i j}(\omega)\right]-r_{i},
\end{aligned}
$$

where $p_{i j}(\omega)$ is the price of the variety produced in country $i$ and sold in country $j, q_{i j}(\omega)$ is the quantity of the variety produced in country $i$ and sold in country $j$, and $r_{i}$ is country i's rental rate of capital.

Each firm sets its price to maximize its profit. Then, the price becomes ${ }^{2}$

$$
p_{i i}(\omega)=\frac{a \sigma}{\sigma-1}, p_{i j}(\omega)=\frac{\tau a \sigma}{\sigma-1}, i, j=H, F .
$$

With these prices, we can rewrite country $i$ 's price index, $P_{i}$, in the following way:

$$
P_{i}=\frac{a \sigma}{\sigma-1}\left(n_{i}+\phi n_{j}\right)^{\frac{1}{1-\sigma}}, i, j=H, F, i \neq j,
$$

where $\phi=(\tau)^{1-\sigma}$ represents the freeness of trade, which takes 0 to 1 , while $n_{i}$ is the number of firms located in country $i$. Since each firm uses one unit of capital as the fixed input, $n_{i}$ equals the amount of capital invested in country $i$.

Given the zero profit condition, the rental rate of capital in country $i$ is

$$
r_{i}=\frac{a q_{i}}{\sigma-1}, i=H, F,
$$

${ }^{2}$ Hereafter, since every firm sets the same price, we omit the variety index. where $q_{i}=q_{i i}+\tau q_{i j}$ is the total output of the firms located in country $i$.

Since the market must be clear, $q_{i}$, is written as

$$
q_{i}=\mu\left[\frac{E_{i}}{P_{i}}\left(\frac{P_{i}}{p_{i i}}\right)^{\sigma}+\frac{\phi E_{j}}{P_{j}}\left(\frac{P_{j}}{p_{i i}}\right)^{\sigma}\right], i, j=H, F, i \neq j,
$$

where $E_{i}$ is the total expenditure of country $i$.

Using the above results, we can obtain the rental rate of capital in country $i$ in the following way:

$$
r_{i}=\frac{\mu}{\sigma}\left[\frac{E_{i}}{n_{i}+\phi n_{j}}+\frac{\phi E_{j}}{\phi n_{i}+n_{j}}\right], i, j=H, F, i \neq j .
$$

\section{Adjustment Process to Spatial Equilibria}

For convenience, hereafter, we normalize the values of labor and capital to unity and consider the model according to a share basis. We also introduce a new variable, $\lambda_{H}$, which represents the share of capital invested in the Home country.

To consider the adjustment process of capital, following standard NEG models, we introduce the following adjustment process:

$$
\dot{\lambda}_{H}=a_{K}\left[r_{H}-r_{F}\right] \lambda_{H}\left(1-\lambda_{H}\right),
$$

where $a_{K}(>0)$ is the adjustment speed parameter of capital. With these dynamics and by using Equation (4) and certain calculations, we can obtain the following result:

$$
\dot{\lambda}_{H} \gtreqless 0 \text { as } s_{H}+\frac{\phi\left(2 s_{H}-1\right)}{1-\phi} \gtreqless \lambda_{H},
$$

where $s_{H}$ is the share of labor in the Home country. This result shows the direction of the adjustment of capital.

Next, we consider the adjustment process of labor. Because wages are fixed to unity, the real income of a worker who lives in country $i$ and invests in country $j$ becomes $\left(1+r_{j}\right) / P_{i}^{\mu}, i, j=H, F$. Workers prefer the country in which they can earn higher real incomes with the given investment destinations. Therefore, we consider the following dynamics:

$$
\begin{aligned}
\dot{S}_{H}= & {\left[a_{L}^{H}\left[\frac{1+r_{H}}{P_{H}^{\mu}}-\frac{1+r_{H}}{P_{F}^{\mu}}\right]+a_{L}^{F}\left[\frac{1+r_{F}}{P_{H}^{\mu}}-\frac{1+r_{F}}{P_{F}^{\mu}}\right]\right] } \\
& S_{H}\left(1-S_{H}\right),
\end{aligned}
$$

where $a_{L}^{H}>0\left(a_{L}^{F}>0\right)$ is the adjustment speed parameter of labor in the Home (Foreign) country. The point of this adjustment process is to show that under the situation of not changing where to invest, each worker chooses his or her residence by comparing levels of real income. We can thus easily show the direction of the 
adjustment of labor as follows:

$$
\dot{s}_{H} \gtreqless 0 \text { as } \lambda_{H} \gtreqless \frac{1}{2} \text {. }
$$

From Equations (5) and (6), we can draw a phase diagram as Figure $\mathbf{1}^{3}$. We can use this adjustment process to explain two cases. First, let us consider the case that the initial value of $\left(s_{H}, \lambda_{H}\right)$ is at point $A$ in Figure 1. Because the initial value is not on the saddle path, the full agglomeration to the Home country occurs in the long run. At first glance, when we see that the final configuration of the spatial structure is the full agglomeration, we may consider that both labor and capital monotonically move to the Home country. However, this is not necessarily true. It is also possible that while capital moves to the Home country, labor moves to the Foreign country. Since the amount of capital is small relative to the size of labor under the line $\dot{\lambda}_{H}=0$, the rental rate of capital in the Home country is higher than that in the Foreign country. This leads to the relocation of capital from the Foreign country to the Home country.

By contrast, under the line $\dot{s}_{H}=0$, the number of firms located in the Home country is absolutely small, and workers living in the Home country change their residences to the Foreign country. Then the share of labor in the Home country decreases. After crossing line $\dot{s}_{H}=0$, both labor and capital increase in the Home country because while the amount of capital relative to the size of labor in the Home country is small, the amount of capital invested in the Home country is absolutely larger than that in the Foreign country. Then, since

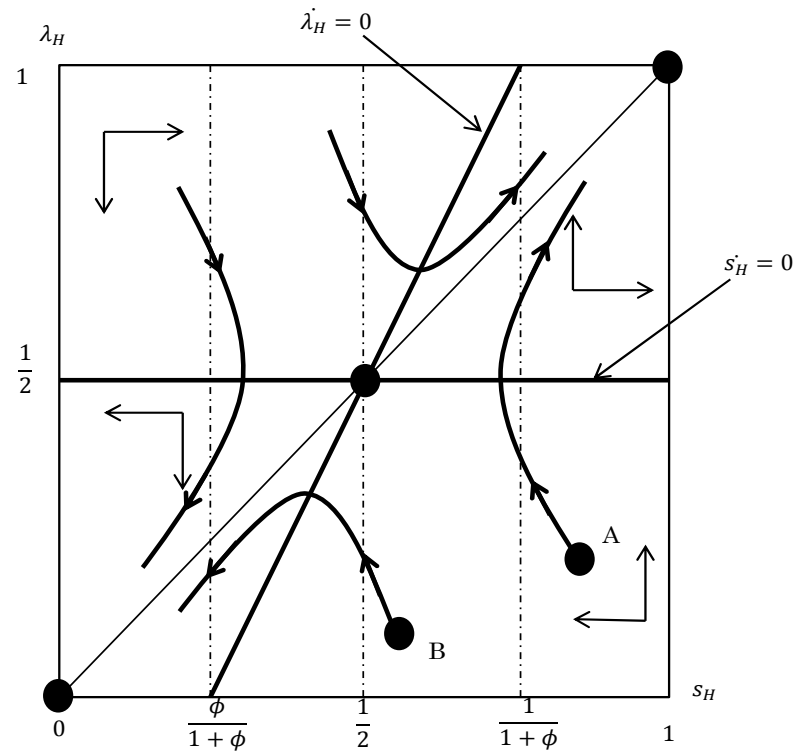

Figure 1. Phase diagram and dynamic paths.

${ }^{3}$ Point $\left(s_{H}, \lambda_{H}\right)=(1 / 2,1 / 2)$ is a saddle point. Proof on the existence of the saddle path would be provided on request. the location of the Home country is attractive for both labor and capital, both factors move to the Home country.

Next, we consider the second case, namely when the initial value of $\left(s_{H}, \lambda_{H}\right)$ is at point $B$ in Figure 1. Because the initial value is not on the saddle path, the full agglomeration equilibrium to the Foreign country occurs in the long run. As in the first case, the adjustment process is not monotonic. In the right-hand area of the line $\dot{\lambda}_{H}=0$, since the size of labor is abundant relative to the amount of capital, capital flows into the Home country. However, because the number of firms located in the Home country is absolutely smaller than that in the Foreign country, workers change their residences from the Home country to the Foreign country. After crossing line $\dot{\lambda}_{H}=0$, while the amount of capital is absolutely small in the Home country, it is large relative to the size of labor, and thus, both factors move to the Foreign country.

In these ways, both factors change locations according to the factor endowment differentials and interact with each other in their adjustment processes. Finally, we refer to the role of transportation cost, which is a key parameter in the NEG model. Although transportation cost plays an important role in determining the slope of $\dot{\lambda}_{H}=0$, it does not affect the adjustment process qualitatively at all.

\section{Conclusions}

In this paper, we presented a phase diagram in order to show the dynamic paths of agglomeration.

Under the situation that two factors are mobile, we showed that adjustment processes of these two factors interact with each other, and thus, they become complicated. Moreover, the adjustment process is not always monotonic. In particular, we showed that even if economic activities are ultimately agglomerated only to one country, it is possible that, on this transition path, the two factors change their locations by moving in opposite directions.

Our analysis is tentative, and hence, there are many remaining issues. We point out only two extensions here. First, in our model, if the economy is not on the saddle path, full agglomeration to one country always occurs. This result may be extreme. To analyze the dispersion of economic activity, the present model could be extended to incorporate immobile factors such as land. Second, we assume a myopic adjustment process for simplicity. If we consider expectation in the location decision, the adjustment process radically changes (e.g., Baldwin [4]; Krugman [5]). We intend to consider how our results might be modified by introducing such topics in future research. 


\section{Acknowledgements}

The authors thanks to Noritsugu Nakanishi, Nobuaki Hamaguchi, Fumio Dei, Yasukazu Ichino, Takashi Shibata, Yang Xi, Chihiro Inaba, Miwa Nakai and participants of Rokko Forum at Kobe University, the 23th KMSG at Kushiro Public University of Economics and the seminar at Konan University. The second author was a JSPS research fellow and this work was financially supported by Grant-in-Aid for JSPS Fellows (No. 10J02314). This work was also supported in part by Grants for Excellent Graduate Schools, MEXT, Japan. Needless to say, any errors remaining in this paper are the responsibility of the authors.

\section{REFERENCES}

[1] R. E. Baldwin and A. J. Venables, "International Migra- tion, Capital Mobility and Transitional Dynamics,” Economica, Vol. 61, No. 243, 1994, pp. 285-300. http://dx.doi.org/10.2307/2554616

[2] P. Martin and C. A. Rogers, "Industrial Location and Public Infrastructure,” Journal of International Economics, Vol. 39, No. 3-4, 1995, pp. 335-351. http://dx.doi.org/10.1016/0022-1996(95)01376-6

[3] A. K. Dixit and J. E. Stiglitz, "Monopolistic Competition and Optimum Product Diversity," American Economic Review, Vol. 67, No. 3, 1977, pp. 297-308.

[4] R. E. Baldwin, "Core-Periphery Model with ForwardLooking Expectations,” Regional Science and Urban Economics, Vol. 31, No. 1, 2001, pp. 21-49. http://dx.doi.org/10.1016/S0166-0462(00)00068-5

[5] P. Krugman, "History versus Expectations," Quarterly Journal of Economics, Vol. 106, No. 2, 1991, pp. 651667. http://dx.doi.org/10.2307/2937950 